\title{
Mass spectrometric identification of proteins released from mitochondria undergoing permeability transition
}

\author{
SD Patterson ${ }^{1}$, CS Spahr ${ }^{1}$, E Daugas ${ }^{2}$, SA Susin ${ }^{2}$, \\ T Irinopoulou ${ }^{3}$, C Koehler ${ }^{4}$ and G Kroemer ${ }^{\star, 2}$ \\ 1 Amgen Inc., Mammalian Genomics, Amgen Center, Thousand Oaks, California \\ 91320, USA \\ 2 Centre National de la Recherche Scientifique, ERS1984, 19 rue Guy Môquet, \\ F-94801 Villejuif, France \\ 3 INSERM U430, Hôpital Broussais, 14 rue Didot; F-75014 Paris, France \\ ${ }^{4}$ Department of Chemistry and Biochemistry, Box 951569, University of \\ California, Los Angeles, California 90095, USA \\ * Corresponding author: G Kroemer, 19 rue Guy Môquet, B.P. 8, F-94801 \\ Villejuif, France. Tel: 33-1-49 5835 13; Fax: 33-1-49 5835 09; \\ E-mail:kroemer@infobiogen.fr
}

Received 25.10.99; revised 12.11.99; accepted 12.11 .99

Edited by R Knight

\begin{abstract}
Mitochondrial membrane permeabilization is a rate-limiting step of cell death. This process is, at least in part, mediated by opening of the permeability transition pore complex (PTPC) Several soluble proteins from the mitochondrial intermembrane space and matrix are involved in the activation of catabolic hydrolases including caspases and nucleases. We therefore investigated the composition of a mixture of proteins released from purified mitochondria upon PTPC opening. This mixture was subjected to a novel proteomics/mass spectrometric approach designed to identify a maximum of peptides. Peptides from a total of 79 known proteins or genes were identified. In addition, 21 matches with expressed sequence tags (EST) were obtained. Among the known proteins, several may have indirect or direct pro-apoptotic properties. Thus endozepine, a ligand of the peripheral benzodiazepin receptor (whose occupation may facilitate mitochondrial membrane permeabilization), was found among the released proteins. Several proteins involved in protein import were also released, namely the so-called X-linked deafness dystonia protein (DDP) and the glucose regulated protein 75 (grb75), meaning that protein import may become irreversibly disrupted in mitochondria of apoptotic cells. In addition, a number of catabolic enzymes are detected: arginase 1 (which degrades arginine), sulfite oxidase (which degrades sulfur amino acids), and epoxide hydrolase. Although the functional impact of each of these proteins on apoptosis remains elusive, the present data bank of mitochondrial proteins released upon PTPC opening should help further elucidation of the death process. Cell Death and Differentiation (2000) 7, 137-144.
\end{abstract}

Keywords: apoptosis; cytochrome c; mitochondria; permeability transition; mass spectrometry; proteomics
Abbreviations: AIF, apoptosis inducing factor; ANT, adenine nucleotide translocator; DDP, X-linked deafness dystonia protein; MS, mass spectrometry; PTPC, permeability transition pore complex; SIMPs, soluble intermembrane space proteins; VDAC, voltage dependent anion channel

\section{Introduction}

Apoptosis is (almost) uniformly accompanied by an increase in mitochondrial membrane permeability, ${ }^{1,2}$ that is triggered by an ever increasing number of different pro-apoptotic effectors, including caspases, ${ }^{3,4}$ pro-apoptotic members of the $\mathrm{Bcl}-2 / \mathrm{Bax}$ family, ${ }^{5-7}$ lipid second messengers such as ganglioside $\mathrm{GD} 3,{ }^{8} \mathrm{Ca}^{2+}$, or pro-oxidants. ${ }^{9-11}$ The permeabilization of the inner membrane is partial, allowing for the free diffusion of solutes of up to $1500 \mathrm{Da}$ and may be reversible. ${ }^{1,2}$ In contrast, permeabilization of the outer membrane is complete, culminating in the release of soluble intermembrane space proteins (SIMPs). The mechanism accounting for membrane permeabilization is a matter of debate. At least in some models, it involves proteins of the permeability transition pore complex (PTPC) whose most abundant components, the voltage dependent anion channel (VDAC) and the adenine nucleotide translocator (ANT), interact with pro- and anti-apoptotic members of the Bcl-2/Bax family. ${ }^{6,12}$ How SIMPs are released from mitochondria is not understood. According to one hypothesis, the liberation of SIMPs may result from ANT-mediated inner membrane permeabilization $^{6,13}$ with consequent matrix swelling and physical disruption of the outer membrane. ${ }^{14}$ However, it has also been suggested that VDAC may form a protein-permeable conduit. $^{12}$

Irrespective of the exact mode of outer membrane permeabilization, it appears that the release of SIMPs occurs in a non-selective fashion and indistinguishably affects relatively small proteins such as cytochrome $c$ $(14.5 \mathrm{kDa}),{ }^{15}$ as well as larger proteins such as the adenylate kinase-2 (50 kDa), ${ }^{16,17}$ apoptosis inducing factor (AIF, $57 \mathrm{kDa}){ }^{18,19}$ and mitochondrial caspases (up to $50 \mathrm{kDa}){ }^{20,21}$ Several among these SIMPs are highly apoptogenic, thus providing a molecular link between mitochondrial dysfunction and the activation of catabolic hydrolases. Thus, cytochrome $c$ and hsp 10 (which translocate into the cytosol) participate in the activation of caspases within the apoptosome ${ }^{15,22}$ whereas AIF (which translocates into the nucleus) activates endonucleases and may account for caspase-independent large scale chromatin condensation. ${ }^{19,23}$

Intrigued by the fact that several mitochondrial proteins are involved in the apoptotic process, we decided to investigate the composition of a mixture of proteins released from purified mitochondria upon PTPC opening. 
This mixture was subjected to a novel mass spectrometric approach designed to identify as many peptides as possible. ${ }^{24-26}$ Here we report the identification of 97 mitochondrial proteins, some of which may contribute to the cell death cascade.

\section{Results and Discussion}

\section{Creation of a protein data base}

Liquid chromatography coupled to tandem mass spectrometry (LC-MS/MS) was employed to investigate the peptide composition of trypsin-digested supernatants, obtained from mouse liver mitochondria treated with the PTPC-opening agent atractyloside. This supernatant contained multiple proteins with a maximum size of $\sim 80 \mathrm{kDa}$ (Figure 1) and clearly differed in its composition from other submitochondrial fractions. Thus, when compared to the intermembrane space fraction of proteins, a lower content of proteins with a molecular mass greater than $80 \mathrm{kDa}$ and a clear bias in favor of smaller proteins was found (Figure 1). The LC-MS/MS technology was applied either to the unfractionated peptide mixture or to a batch of peptides that had been enriched based on their cysteine content, as detailed in Materials and Methods. Proteins were identified by correlation of their peptide sequence with an uninterpreted MS/MS spectrum. Obvious contaminants (trypsin and 15 peptides corresponding to 10 different ribosomal proteins) were excluded from the pool of proteins which are listed in Table 1. Peptides corresponding to a total of 79 known proteins or genes were identified. In addition, 21 matches with expressed sequence tags (EST) were obtained. Of note, several SIMPs that are known to be released from mouse liver mitochondria exposed to atractyloside (such as AIF or caspases 2 and 9) ${ }^{19,20}$ were not detected, indicating that this protein data base must be regarded as incomplete. These proteins are most likely at levels at or below that of the contaminants (ribosomal proteins) identified in the sample.

As to be expected, most of the proteins whose subcellular localization has been previously assessed are mitochondrial proteins. A lysosomal contamination might be suggested by the detection of cathepsin $B$.

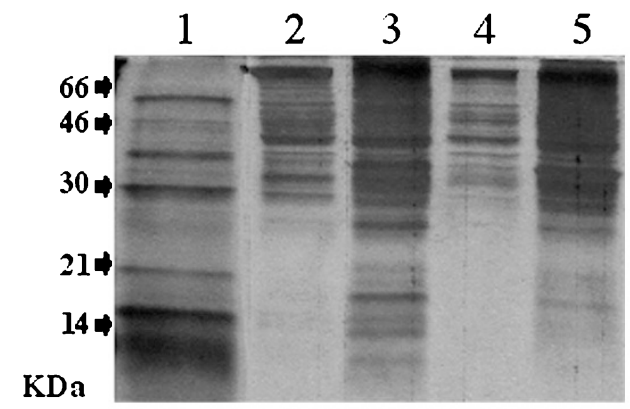

Figure 1 Silver staining profiles of the supernatant of atractyloside treated mouse liver mitochondria as well as submitochondrial fractions. Lane 1: supernatant of atractyloside-treated mitochondria $(5 \mathrm{mM}, 30 \mathrm{~min})$. Lane 2 Inner membrane proteins. Lane 3: intermembrane proteins. Lane 4: outer membrane. Lane 5: matrix
However, cathepsin B has been previously found in the supernatant of atractyloside treated mitochondria, ${ }^{27}$ and this may indicate that some of this protease is actually imported into mitochondria and/or associates with mitochondria. Several proteins which are normally considered as peroxisomal were also detected. Again, it is possible that this is due to a minor contamination of mitochondria with peroxisomes. Alternatively, it may be indicative of a dual (peroxisomal plus mitochondrial) localization of such proteins, which has been observed. ${ }^{28-30}$ A large number of proteins that are classified as matrix proteins were identified. This may constitute a fraction of proteins that are being imported (through the intermembrane space) or, alternatively, suggest that some mitochondria (partially?) lose the integrity of the inner mitochondrial membrane..2,31 In accord with this latter possibility, mitochondria treated with the PTPC activator Bax release the matrix protein aspartate aminotransferase ${ }^{32}$ and some translocation of the matrix protein hsp60 into the cytosol has been reported to occur in cells undergoing apoptosis. ${ }^{22}$ The release of hsp60, however, is not detectable by immunofluorescence staining, indicating that it only affects a minor fraction of the pool of hsp60. ${ }^{22,31}$ We have verified the subcellular localization of two proteins found in the data base, namely X-linked deafness dystonia protein (DDP, which is an intermembrane protein) and SOD2 (which is a matrix protein). As to be expected from their submitochondrial localization, DDP distributed from mitochondria (counterstained with the matrix protein hsp60) to the cytosol when apoptosis was induced (Figure 2A). In contrast, SOD2 remained mitochondrial (Figure 2B), meaning that only a minority of SOD2, if any, was liberated from mitochondria following apoptosis induction.

\section{Concluding remarks}

The data contained in Table 1 confirm the non-selective nature of mitochondrial membrane permeabilization. In addition to known apoptogenic SIMPs, a number of different proteins which might have some impact on cell death were identified. Thus acyl-CoA binding protein (diazepam binding inhibitor, also called endozepine) and a putative analogue (corresponding to EST AA930535) were found in the mitochondrial supernatant. We and others have found in the past that ligation of the mitochondrial benzodiazepine receptor (whose endogenous ligand is acyl-CoA binding protein) causes PT pore opening and favors apoptosis. ${ }^{33-36}$ It is tempting to speculate that endozepine released from mitochondria undergoing PT may affect other mitochondria. Several proteins involved in protein import were also released, namely the so-called $\mathrm{X}$-linked deafness dystonia protein $(\mathrm{DDP})^{37}$ and the glucose regulated protein 75 (grb75). This may imply that protein import becomes disrupted in mitochondria, making the outer membrane damage irreversible. Moreover, grb75 has been reported to interact with $\mathrm{p} 53 .^{38}$ The mass spectrometric data indicate that several antioxidant enzymes were released from 
Table 1 Mass spectrometric identification of mitochondrial proteins

\begin{tabular}{|c|c|c|c|c|c|}
\hline $\begin{array}{l}\text { Accession } \\
\text { Code }\end{array}$ & $\begin{array}{l}\text { Protein } \\
\text { description }\end{array}$ & Species & $\begin{array}{l}\text { Localization } \\
\text { of mature } \\
\text { protein }\end{array}$ & $\begin{array}{l}\text { Peptide or } \\
\text { No. of } \\
\text { peptides* }^{*}\end{array}$ & Occurrences \\
\hline Q64433 & $10 \mathrm{kd}$ heat shock protein, mitochondrial (hsp10) & mouse & intermembrane & 6 & 14 \\
\hline Q64591 & $\begin{array}{l}\text { 2,4-dienoyl-CoA reductase, mitochondrial precursor } \\
\text { (ec 1.3.1.34) }\end{array}$ & rat & mitoch. & 2 & 2 \\
\hline P42125 & $\begin{array}{l}\text { 3,2-trans-enoyl-CoA isomerase, mitochondrial pre- } \\
\text { cursor (ec 5.3.3.8)- }\end{array}$ & mouse & matrix & $\begin{array}{l}\text { VLVETEG- } \\
\text { PAGVAVMK }\end{array}$ & 1 \\
\hline W64336 & 3-ketoacyl-CoA thiolase mitochondrial (ec 2.3.1.16) & mouse & matrix & 12 & 21 \\
\hline P21775 & $\begin{array}{l}\text { 3-ketoacyl-CoA thiolase peroxisomal a precursor } \\
\text { (ec 2.3.1.16) }\end{array}$ & rat & peroxisome & 6 & 13 \\
\hline P07871 & $\begin{array}{l}\text { 3-ketoacyl-CoA thiolase peroxisomal b precursor } \\
\text { (ec 2.3.1.16) }\end{array}$ & rat & matrix & 15 & 25 \\
\hline P20029 & $78 \mathrm{kd}$ glucose regulated protein precursor (grp 78) & mouse & matrix & 2 & 2 \\
\hline P17764 & $\begin{array}{l}\text { acetyl-CoA acetyltransferase precursor, mitochon- } \\
\text { drial (ec 2.3.1.9) }\end{array}$ & rat & matrix & 7 & 15 \\
\hline Q99798 & $\begin{array}{l}\text { aconitate hydratase, mitochondrial precursor } \\
\text { (ec 4.2.1.3) }\end{array}$ & human & mitoch. & 2 & 2 \\
\hline P51174 & $\begin{array}{l}\text { acyl-CoA dehydrogenase, long-chain specific pre- } \\
\text { cursor (ec 1.3.99.13) }\end{array}$ & mouse & mitoch. & $\begin{array}{l}\text { CIGAIAM- } \\
\text { TEPGAG- } \\
\text { SDLQGVR }\end{array}$ & 1 \\
\hline P31786 & $\begin{array}{l}\text { acyl-CoA-binding protein (diazepam binding inhibi- } \\
\text { tor) (endozepine) }\end{array}$ & mouse & mitoch. & 2 & 2 \\
\hline P07872 & acyl-CoA oxidase, peroxisomal (ec 1.3.3.6) & rat & mitoch. & 2 & 2 \\
\hline P54819 & $\begin{array}{l}\text { adenylate kinase isoenzyme } 2 \text {, mitochondrial } \\
\text { (ec } 2.7 .4 .3)\end{array}$ & human & intermembrane & 5 & 7 \\
\hline P46656 & adrenodoxin precursor (adrenal ferredoxin) & mouse & matrix & LGCQVCLTK & 2 \\
\hline AF027730 & alanine:glyoxylate aminotransferase & mouse & $\begin{array}{l}\text { mitoch. } \\
\text { peroxisomes }\end{array}$ & $\begin{array}{l}\text { VIHHTTPVT- } \\
\text { SLYCLR }\end{array}$ & 1 \\
\hline P47738 & $\begin{array}{l}\text { aldehyde dehydrogenase, mitochondrial precursor } \\
\text { (ec 1.2.1.3) }\end{array}$ & mouse & matrix & 9 & 10 \\
\hline P49419 & antiquitin (ec 1.2.1.-) & human & & $\begin{array}{l}\text { GSDCGIVNV- } \\
\text { NIPTSGAEIG- } \\
\text { GAFG }\end{array}$ & 1 \\
\hline Q61176 & arginase 1 (ec 3.5.3.1) & mouse & mitoch. & 6 & 7 \\
\hline P16460 & argininosuccinate synthase (ec 6.3.4.5) & mouse & cytosol & $\begin{array}{l}\text { FELTCYSLAP- } \\
\text { QIK }\end{array}$ & 2 \\
\hline P05202 & $\begin{array}{l}\text { aspartate aminotransferase, mitochondrial precur- } \\
\text { sor (ec 2.6.1.1) }\end{array}$ & mouse & matrix & 7 & 8 \\
\hline Q06185 & ATP synthase e chain, mitochondrial (ec 3.6.1.34) & mouse & inner membrane & $\begin{array}{l}\text { ELAEAQDD- } \\
\text { SILK }\end{array}$ & 1 \\
\hline AF033381 & betaine homocysteine methyl transferase & mouse & cytosol & 7 & 7 \\
\hline P07756 & $\begin{array}{l}\text { carbamoyl-phosphate synthase (ammonia) mito- } \\
\text { chondrial precursor (ec 6.3.4.16) }\end{array}$ & rat & matrix & 33 & 45 \\
\hline P24270 & catalase (ec 1.11.1.6) & mouse & peroxisomes & 24 & 48 \\
\hline P10605 & cathepsin b precursor (ec 3.4.22.1) (cathepsin b1) & mouse & lysosomes & $\begin{array}{l}\text { EQWSNCP- } \\
\text { TIGQIR }\end{array}$ & 1 \\
\hline U90725 & $\begin{array}{l}\text { caveolae-associated protein mRNA; high-density } \\
\text { lipoprotein binding protein }\end{array}$ & rat & caveolae & $\begin{array}{l}\text { LVGEIM- } \\
\text { QETGTR }\end{array}$ & 1 \\
\hline AF004591 & copper transport protein Atox1 (ATOX1) & mouse & & $\begin{array}{l}\text { VCID- } \\
\text { SEHSSDTL- } \\
\text { LATLNK }\end{array}$ & 1 \\
\hline P36552 & $\begin{array}{l}\text { coproporphyrinogen iii oxidase precursor } \\
\text { (ec1.3.3.3.) (coproporphyrinogenase) }\end{array}$ & mouse & mitoch. & 2 & 2 \\
\hline P00009 & cytochrome c & mouse & intermembrane & 6 & 11 \\
\hline Q01205 & dihydrolipoamide succinyltransferase (ec 2.3.1.61) & rat & $\begin{array}{l}\text { inner membrane } \\
\text { maxrix }\end{array}$ & GLVVPVIR & 1 \\
\hline L79910 & dimethylglycine dehydrogenase like protein & rat & matrix & $\begin{array}{l}\text { GAQVIEN- } \\
\text { CAVTGIR }\end{array}$ & 1 \\
\hline P13803 & $\begin{array}{l}\text { electron transfer flavoprotein alpha-subunit precur- } \\
\text { sor }\end{array}$ & rat & inner membrane & 15 & 29 \\
\hline P04720 & elongation factor 1 -alpha 2 (ef-1-alpha-2) & human & $\begin{array}{l}\text { cytoskeleton, } \\
\text { cytosol }\end{array}$ & $\begin{array}{l}\text { IGGIGTVP- } \\
\text { VGR }\end{array}$ & 1 \\
\hline P30084 & $\begin{array}{l}\text { enoyl-CoA hydratase, mitochondrial precursor } \\
\text { (ec 4.2.1.17) }\end{array}$ & human & mitoch. & 3 & 3 \\
\hline
\end{tabular}


Table 1 (Continued)

\begin{tabular}{|c|c|c|c|c|c|}
\hline $\begin{array}{l}\text { Accession } \\
\text { Code }\end{array}$ & $\begin{array}{l}\text { Protein } \\
\text { Description }\end{array}$ & Species & $\begin{array}{l}\text { Localization } \\
\text { of mature } \\
\text { protein }\end{array}$ & $\begin{array}{l}\text { Peptide of } \\
\text { No. of } \\
\text { peptides }\end{array}$ & Occurrences \\
\hline AA472254 & $\begin{array}{l}\text { enoyl-CoA: hydratase-3-hydroxyacyl-CoA dehydro- } \\
\text { genase bifunctional enzyme (similar to } \\
\text { GB:L07077) }\end{array}$ & mouse & $\begin{array}{l}\text { mitoch. } \\
\text { peroxisome }\end{array}$ & LGILDVVVK & 1 \\
\hline P51660 & estradiol 17 beta-dehydrogenase 4 (ec 1.1.1.62) & mouse & & 2 & 2 \\
\hline P12710 & $\begin{array}{l}\text { fatty acid-binding protein, liver (l-fabp) (14 kd } \\
\text { selenium-binding protein) }\end{array}$ & mouse & $\begin{array}{l}\text { mitoch. } \\
\text { cytosol }\end{array}$ & 4 & 6 \\
\hline P00884 & fructose-bisphophate aldolase b (ec 4.1.2.13) & rat & & 5 & 9 \\
\hline P26443 & glutamate dehydrogenase precursor (ec 1.4.1.3) & mouse & matrix & 6 & 8 \\
\hline P11352 & glutathione peroxidase (ec 1.11.1.9) (gshpx-1) & mouse & $\begin{array}{l}\text { mitoch.,cytosol } \\
\text { peroxisome }\end{array}$ & 2 & 2 \\
\hline P23434 & glycine cleavage system $\mathrm{h}$ protein precursor & human & mitoch. & SCYEDGWLIK & 1 \\
\hline P29411 & $\begin{array}{l}\text { gtp:amp phosphotransferase mitochondrial } \\
(\text { ec } 2.7 .4 .10)\end{array}$ & rat & mitoch. & $\begin{array}{l}\text { AYEAQ- } \\
\text { TEPVLQYYQK }\end{array}$ & 1 \\
\hline P34931 & heat shock 70 kd protein 1-hom (hsp70 hom) & human & & $\begin{array}{l}\text { TTPSYVAFTD- } \\
\text { TER }\end{array}$ & 2 \\
\hline P52760 & heat-responsive protein 12 & mouse & & $\begin{array}{l}\text { APAAIGPYS- } \\
\text { QAVQVDR }\end{array}$ & 2 \\
\hline Q00341 & $\begin{array}{l}\text { high density lipiprotein binding protein (hdl-binding } \\
\text { protein) }\end{array}$ & human & & 2 & 3 \\
\hline P38060 & $\begin{array}{l}\text { hydroxymethylglutaryl-CoA lyase precursor } \\
\text { (ec 4.1.3.4) }\end{array}$ & mouse & $\begin{array}{l}\text { mitoch. } \\
\text { peroxisomes }\end{array}$ & $\begin{array}{l}\text { EVSVFGAV- } \\
\text { SELFTR }\end{array}$ & 1 \\
\hline P54869 & $\begin{array}{l}\text { Hydroxymethylglutaryl-CoA synthase, mitochondrial } \\
\text { precursor }(4.1 .3 .5)\end{array}$ & mouse & mitoch. & 2 & 2 \\
\hline P12007 & $\begin{array}{l}\text { isovaleryl-CoA dehydrogenase precursor } \\
(\text { ec } 1.3 .99 .10)\end{array}$ & rat & matrix & 2 & 3 \\
\hline M89644 & keratin $\mathrm{K} 5$ & rat & cytoskeleton & $\begin{array}{l}\text { SLDLDSII- } \\
\text { AEVK }\end{array}$ & 1 \\
\hline A61281 & lysozyme homolog AT 2, bone & rat & & $\begin{array}{l}\text { NTDGSTDY- } \\
\text { GILQINSR }\end{array}$ & 1 \\
\hline W11382 & $\begin{array}{l}\text { ma86g01.r1 Soares mouse p3NMF19. W11382 } \\
\text { Frame }+3\end{array}$ & mouse & & $\begin{array}{l}\text { VTHLSTLQV- } \\
\text { GSLSVK }\end{array}$ & 1 \\
\hline P08249 & $\begin{array}{l}\text { malate dehydrogenase, mitochondrial precursor } \\
\text { [acylating] (ec 1.2.1.27) }\end{array}$ & mouse & matrix & 12 & 16 \\
\hline Q02253 & $\begin{array}{l}\text { methylmalonate-semialdehyde dehydrogenase pre- } \\
\text { cursor [acylating] (ec 1.2.1.27) }\end{array}$ & rat & mitoch. & 3 & 3 \\
\hline P19226 & $\begin{array}{l}\text { mitochondrial matrix protein } \mathrm{p} 1 \text { precursor ( } \mathrm{p} 60 \\
\text { lymphocyte protein) }\end{array}$ & mouse & matrix & 16 & 27 \\
\hline P38646 & $\begin{array}{l}\text { mitochondrial stress-70 protein precursor }(75 \mathrm{kd} \\
\text { glucose regulated protein) }\end{array}$ & human & mitoch. & 7 & 10 \\
\hline P20108 & $\begin{array}{l}\text { mitochondrial thioredoxin-dependent peroxide re- } \\
\text { ductase precursor }\end{array}$ & mouse & mitoch. & $\begin{array}{l}\text { GLFIIDPN- } \\
\text { GVVK }\end{array}$ & 1 \\
\hline P32020 & $\begin{array}{l}\text { nonspecific lipid-transfer protein precursor (sterol } \\
\text { carrier protein 2) }\end{array}$ & mouse & $\begin{array}{l}\text { mitoch. } \\
\text { peroxisome }\end{array}$ & 15 & 45 \\
\hline P15531 & nucleoside diphosphate kinase a (ec 2.7.4.6) & human & $\begin{array}{l}\text { matrix } \\
\text { nuclear }\end{array}$ & 4 & 5 \\
\hline P11725 & $\begin{array}{l}\text { ornithine carbamolyltransferase precursor } \\
\text { (ec 2.1.3.3) }\end{array}$ & mouse & mitoch. & 4 & 4 \\
\hline P05092 & $\begin{array}{l}\text { peptidyl-prolyl cis-trans isomerase a (ec 5.2.1.8) } \\
\text { (cycophilin A) }\end{array}$ & human & cytosol & $\begin{array}{l}\text { HTGPGILSMA- } \\
\text { NAGPNTNGS- } \\
\text { QFFICTAK }\end{array}$ & 1 \\
\hline AF006688 & peroxisomal acyl-CoA oxidase & mouse & peroxisome & 2 & 2 \\
\hline P29341 & $\begin{array}{l}\text { polyadenylate-binding protein } 1 \text { (poly(a) binding } \\
\text { protein 1) }\end{array}$ & mouse & cytosol & 6 & 7 \\
\hline P09103 & $\begin{array}{l}\text { protein disulfide isomerase precursor (pdi) } \\
\text { (ec5.3.4.1) (prolyl 4-hydroxylase }\end{array}$ & mouse & ER & $\begin{array}{l}\text { VDATEES- } \\
\text { DLAQQYGVR }\end{array}$ & 1 \\
\hline P99029 & $\begin{array}{l}\text { putative peroxisomal antioxidant enzyme (liver } \\
\text { tissue } 2 \text { d-page spot } 2 d-0014 \text { iv) }\end{array}$ & mouse & peroxisome & 2 & 2 \\
\hline Q05920 & pyruvate carboxylase precursor (ec 6.4.1.1) & mouse & matrix & 2 & 2 \\
\hline P09139 & $\begin{array}{l}\text { serine-pyruvate aminotransferase, mitochondrial } \\
\text { percursor (ec 2.6.1.51) }\end{array}$ & & mitoch & $\begin{array}{l}\text { LLLGPGSN- } \\
\text { LAPR }\end{array}$ & 1 \\
\hline P34914 & $\begin{array}{l}\text { soluble epoxide hydrolase (ec 3.3.2.3) (epoxide } \\
\text { hydratase) }\end{array}$ & mouse & $\begin{array}{l}\text { cytosol, perox. } \\
\text { mitoch. }\end{array}$ & 2 & 2 \\
\hline
\end{tabular}


Table 1 (Continued)

\begin{tabular}{|c|c|c|c|c|c|}
\hline $\begin{array}{l}\text { Accession } \\
\text { Code }\end{array}$ & $\begin{array}{l}\text { Protein } \\
\text { Description }\end{array}$ & Species & $\begin{array}{l}\text { Localization } \\
\text { of mature } \\
\text { protein }\end{array}$ & $\begin{array}{l}\text { Peptide of } \\
\text { No. of } \\
\text { peptides }\end{array}$ & Occurrences \\
\hline P13086 & $\begin{array}{l}\text { succinyl-CoA ligase, alpha-chain precursor (ec } \\
6.2 .1 .4)\end{array}$ & rat & mitoch. & 2 & 3 \\
\hline Q07116 & sulfite oxidase precursor (ec 1.8.3.1) & rat & intermembrane & $\begin{array}{l}\text { LCDVLA- } \\
\text { QAGHR }\end{array}$ & 2 \\
\hline P07895 & superoxide dismutase $[\mathrm{mn}]$ precursor (ec 1.15.1.1) & rat & matrix & $\begin{array}{l}\text { GDVTTQVAL- } \\
\text { QPALK }\end{array}$ & 1 \\
\hline P10639 & thioredoxin & mouse & & 2 & 2 \\
\hline Q06830 & thioredoxin peroxidase 2 & human & & 4 & 10 \\
\hline P52196 & $\begin{array}{l}\text { thiosulfate sulfurtransferase (ec 2.8.1.1) (rhoda- } \\
\text { nese) }\end{array}$ & mouse & matrix & 5 & 6 \\
\hline P25688 & uricase (ec 1.7.3.3) & mouse & peroxisomes & 2 & 2 \\
\hline AF086630 & VAMP-associated protein A & rat & & 3 & 3 \\
\hline U66035 & X-linked deafness dystonia protein (DDP) & human & intermembrane & 4 & 6 \\
\hline Al663509 & uk33g02.y1, Sugano mouse kidney mkia Frame+2 & mouse & & $\begin{array}{l}\text { MSGGSLIPSP- } \\
\text { NQQALSPQP- } \\
\text { SR }\end{array}$ & 1 \\
\hline AF066751 & $\begin{array}{l}\mathrm{ES} / 130 \mathrm{mRNA} \text {, complete cds; similar to } 180 \mathrm{~K} \\
\text { ribosome receptor and cardiac morphogenesis } \\
\text { protein } \mathrm{ES} / 130\end{array}$ & human & & 3 & 4 \\
\hline Н35434 & $\begin{array}{l}\text { EST105154 Rat PC-12 cells, untre H35434 Frame } \\
+3\end{array}$ & rat & & $\begin{array}{l}\text { AGIVQDEVQ- } \\
\text { PPGLK }\end{array}$ & 2 \\
\hline W08097 & $\begin{array}{l}\text { mb39c09.r1 Soares mouse p3NMF19. W08097 } \\
\text { Frame }+1\end{array}$ & mouse & & 2 & 2 \\
\hline W07953 & $\begin{array}{l}\text { mb45g02.r1 Soares mouse p3NMF19. W07953 } \\
\text { Frame }+2\end{array}$ & mouse & & $\begin{array}{l}\text { AVATLQ- } \\
\text { GEGLSVT- } \\
\text { GIVCHVGK }\end{array}$ & 1 \\
\hline W29591 & $\begin{array}{l}\text { mc08a08.r1 Soares mouse p3NMF19. W29591 } \\
\text { Frame }+1\end{array}$ & mouse & & $\begin{array}{l}\text { RDPVDTDDT- } \\
\text { ATALR }\end{array}$ & 2 \\
\hline W62507 & $\begin{array}{l}\text { md72e10.r1 Soares mouse embryo N W62507 } \\
\text { Frame }+1\end{array}$ & mouse & & $\begin{array}{l}\text { GTPEQPCGF- } \\
\text { SNAVVQILR }\end{array}$ & 1 \\
\hline W66688 & $\begin{array}{l}\text { me26a03.r1 Soares mouse embryo N W66688 } \\
\text { Frame }+1\end{array}$ & mouse & & 3 & 6 \\
\hline W97106 & $\begin{array}{l}\text { mf90a04.r1 Soares mouse embryo N W97106 } \\
\text { Frame }+3\end{array}$ & mouse & & $\begin{array}{l}\text { ASQQDFE- } \\
\text { NALNQVK }\end{array}$ & 1 \\
\hline AA008039 & $\begin{array}{l}\text { mg71f09.r1 Soares mouse embryo AA008039 } \\
\text { Frame }+2\end{array}$ & mouse & & $\begin{array}{l}\text { FDSNVSGQS- } \\
\text { SFGTSPAAD- } \\
\text { NIEK }\end{array}$ & 2 \\
\hline AA004027 & $\begin{array}{l}\text { mg80g01.r1 Soares mouse embryo AA004027 } \\
\text { Frame +2 }\end{array}$ & mouse & & $\begin{array}{l}\text { VQIAVANA- } \\
\text { QELLQR }\end{array}$ & 1 \\
\hline AA109583 & $\begin{array}{l}\text { ml97h06.r1 Stratagene mouse ki AA109583 } \\
\text { Frame }+3\end{array}$ & mouse & & $\begin{array}{l}\text { FLYTVPNGN- } \\
\text { NPTGNS- } \\
\text { LTGDR }\end{array}$ & 1 \\
\hline AA109917 & $\begin{array}{l}\text { mp49h11.r1 Barstead MPLRB1 Mus AA109917 } \\
\text { Frame }+3\end{array}$ & mouse & & $\begin{array}{l}\text { NHLPVPNLD- } \\
\text { PHTYR }\end{array}$ & 1 \\
\hline AA222445 & $\begin{array}{l}\text { my } 18 \mathrm{~g} 05 . \mathrm{r} 1 \text { Barstead mouse hear AA222445 } \\
\text { Frame +2 }\end{array}$ & mouse & & $\begin{array}{l}\text { IPNQFQGSP- } \\
\text { PTPSDESVK }\end{array}$ & 2 \\
\hline AA254902 & $\begin{array}{l}\text { mz78f08.r1 Soares mouse NML My AA254902 } \\
\text { Frame }+1\end{array}$ & mouse & & $\begin{array}{l}\text { NQEAMGAF- } \\
\text { QEFPQ- } \\
\text { VEACR }\end{array}$ & 1 \\
\hline AA939535 & $\begin{array}{l}\text { vsbob01.r1, similar to SW: ENDR_BOVIN POT106 } \\
\text { Endozepine related protein precursor }\end{array}$ & mouse & & 2 & 2 \\
\hline W42142 & similar to PIR:S16967 NADH dehydrogenase & mouse & & 2 & 2 \\
\hline W54192 & $\begin{array}{l}\text { similar to SW: YA94_SCHPO Q09783 Hypothetical } \\
11.4 \text { kD protein }\end{array}$ & mouse & & $\begin{array}{l}\text { CIGKPGGSL- } \\
\text { DNSEQK }\end{array}$ & 2 \\
\hline AA261575 & $\begin{array}{l}\text { similar to WP:B0334.3A CE02934 Oxalyl0CoA } \\
\text { decarboxylase }\end{array}$ & mouse & & TPEELQHSLR & 1 \\
\hline AA002289 & similar to WP:C16C10.11 CE01491 & mouse & & $\begin{array}{l}\text { QFLECAQNQ- } \\
\text { SDVK }\end{array}$ & 2 \\
\hline H20248 & $\begin{array}{l}\text { yn56g04.r1 Homo sapiens cDNA clo H20248 } \\
\text { Frame }+1\end{array}$ & human & & $\begin{array}{l}\text { LLADPT- } \\
\text { GAFGK }\end{array}$ & 1 \\
\hline TOTALS: & $\begin{array}{r}\text { Total \# proteins/genes }=97 \\
\text { \# Known proteins/genes }=76 \\
\text { \# EST matches }=21\end{array}$ & & & 298 & 255 \\
\hline
\end{tabular}

*Peptide sequences are listed when only one set of mass spectroscopic data matched the corresponding data bank entry. In the case of more than one match, their number is specified 

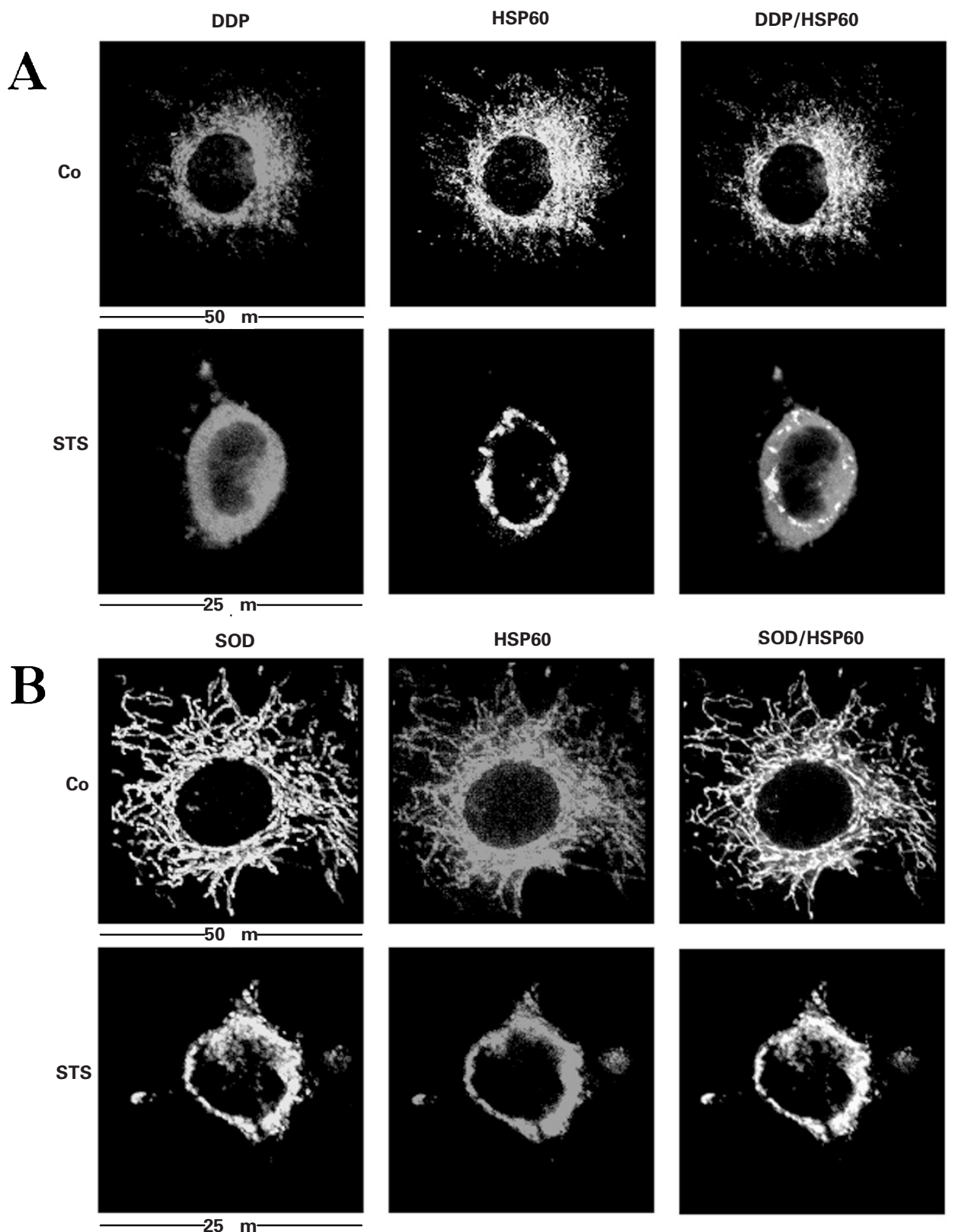

Figure 2 Subcellular distribution of DDP and SOD2 in cells undergoing apoptosis. Cells cultured in the absence (Co.) or presence of the apoptosis inducer STS were stained with antibodies specific for $\operatorname{DDP}(\mathbf{A})$ or SOD2 (B) and counterstained for the mitochondral matrix protein Hsp60. Note that the overlap between DDP and Hsp60 dependent fluorescence found in normal cells is largely abolished in apoptotic cells. In contrast, this overlap persists for SOD2 and Hsp60, even after induction of apoptosis

mitochondria. This applies to glutathione peroxidase, thioredoxin, thioredoxin peroxidase, and perhaps a fraction of manganese-dependent superoxide dismutase (SOD2), suggesting a relative deprotection of mitochondrial membranes from oxidative reactions. Accordingly, an enhanced local generation of superoxide anion and the oxidation of mitochondrial cardiolipin has been found to occur shortly after mitochondrial membrane permeabilization in intact cells. ${ }^{39}$ Finally, a number of catabolic enzymes are detected in the SIMPs fraction: arginase 1 (which degrades arginine), sulfite oxidase (which degrades sulfur amino acids), and epoxide hydrolase. Such enzymes might deplete essential metabolites, thereby decreasing anabolic reactions and/or affecting energy metabolism.

The evaluation of each of these proteins in the context of apoptosis remains elusive. However, the data base of mitochondrial proteins contained in this article should prove useful for further investigation of cell death mechanisms. 


\section{Materials and Methods}

\section{Preparation of protein samples}

Mitochondria (1 $\mathrm{mg}$ protein $/ \mathrm{ml}$ ) were purified from mouse liver on a Percoll gradient as previously described, ${ }^{40}$ resuspended in CFS buffer (220 mM mannitol; $68 \mathrm{mM}$ sucrose, $2 \mathrm{mM} \mathrm{NaCl}, 2.5 \mathrm{mM} \mathrm{KH}_{2} \mathrm{PO}_{4}$, $0.5 \mathrm{mM}$ EGTA, $2 \mathrm{mM} \mathrm{MgCl}$, $5 \mathrm{mM}$ pyruvate, $0.1 \mathrm{mM}$ phenylmethyl sulfonylfluoride, $1 \mu \mathrm{g} / \mathrm{ml}$ leupeptin, $1 \mu \mathrm{g} / \mathrm{ml}$ pepstatin A, $50 \mu \mathrm{g} / \mathrm{ml}$ antipain, $10 \mu \mathrm{g} / \mathrm{ml}$ chymopapain, $1 \mathrm{mM}$ dithiotreitol, $10 \mathrm{mM}$ HEPES$\mathrm{NaOH}, \mathrm{pH} 7.4)$ and incubated in the presence of atractyloside $(5 \mathrm{mM}$, $30 \mathrm{~min}, \mathrm{RT})$, followed by centrifugation $\left(7000 \times \mathrm{g}, 10 \mathrm{~min}, 4^{\circ} \mathrm{C}\right)$, recovery of the supernatant and ultracentrifugation $\left(1.5 \times 10^{5} \times \mathrm{g}\right.$, $\left.1 \mathrm{~h}, 4^{\circ} \mathrm{C}\right)$. This sample was subjected to LC-MS/MS. In addition, submitochondrial fractions were purified by standard procedures ${ }^{41}$ and the samples were analyzed by SDS-PAGE (15\%), followed by silver staining.

\section{LC-MS/MS of unfractionated proteins}

Forty $\mu \mathrm{g}$ of protein was dried, resuspended in $500 \mu \mathrm{L}$ of $30 \mathrm{mM}$ Tris$\mathrm{HCl}, \mathrm{pH} 7.0 / 8 \mathrm{M}$ urea/10 mM dithiotreitol, and incubated for $30 \mathrm{~min}$ at $37^{\circ} \mathrm{C}$. The sample was alkylated with $20 \mathrm{mM}$ iodoacetamide for $30 \mathrm{~min}$ at room temperature in the dark, then buffer exchanged into $30 \mathrm{mM}$ Tris- $\mathrm{HCl}, \mathrm{pH}$ 7.0/2 $\mathrm{M}$ urea at $4^{\circ} \mathrm{C}$ using a Centricon YM-3 (3,000 MW cutoff, Amicon, Beverly, MA, USA). Digestion was initiated with the addition of $1.5 \mu \mathrm{g}$ trypsin (Sequencing Grade, Boehringer Mannheim, Indianapolis, IN, USA) and incubated overnight at $37^{\circ} \mathrm{C}$. The digest was acidified with $30 \mu \mathrm{L} 10 \%$ TFA. LC-MS/MS analysis was performed using a Hewlett Packard 1100 HPLC system (Hewlett-Packard, Palo Alto, CA, USA) connected on-line with a 1:1 splitter to a Finnigan LCQ iontrap mass spectrometer (Thermoquest, San Jose, CA, USA) as described. ${ }^{42}$ Peptides were separated on a C18 $1.0 \times 250 \mathrm{~mm}$ column (Vydac, Hesperia, CA, USA) using a flow rate of $60 \mu \mathrm{l} / \mathrm{min}$, with the UV monitored at $215 \mathrm{~nm}$. Solvent $A$ was $0.1 \%$ formic $\mathrm{acid} / \mathrm{H}_{2} \mathrm{O}$, and solvent $B$ was $0.09 \%$ formic acid $/ \mathrm{H}_{2} \mathrm{O} / 90 \%$ acetonitrile. The gradient consisted of $3 \% \mathrm{~B}$ isocratic for $15 \mathrm{~min}$, a linear gradient to $60 \% \mathrm{~B}$ in $57 \mathrm{~min}$, to $90 \% \mathrm{~B}$ in $15 \mathrm{~min}$, isocratic at $90 \% \mathrm{~B}$ for $15 \mathrm{~min}$, and then to $3 \% \mathrm{~B}$ in $5 \mathrm{~min}$. To determine the amount to load for subsequent runs, an aliquot of the digest $(\sim 8 \mu \mathrm{g})$ was analyzed using the 'triple play' feature for data-dependent ion selection and fragmentation (MS, zoom MS, MS/MS) with precursor ion selection over the mass range $400-$ $2000 \mathrm{~m} / \mathrm{z}$. With the Finnigan Navigator software (Thermoquest, San Jose, CA, USA), an isotope exclusion width of 5 and a dynamic exclusion time of 1.0 min were utilized and a relative collision energy of 40 was set. The remaining digest $(\sim 32 \mu \mathrm{g})$ was aliquoted into three samples and analyzed as above but with different ion selection criteria. The ion selection criteria for the triple play utilized one of the mass ranges of $400-615,585-815$, and $785-2000 \mathrm{~m} / \mathrm{z}$ for each analysis. Finnigan.RAW files were converted to .txt files, then fragment ion spectra were searched against non-redundant protein sequence and translations of EST databases. ${ }^{42,43}$ Potential peptide matches were visually confirmed.

\section{Reversible cysteine biotinylation of peptide mixture}

One-hundred-and-twenty $\mu \mathrm{g}$ sample was vacuum concentrated and resuspended in $1 \mathrm{~mL}$ of $40 \mathrm{mM}$ Tris- $\mathrm{HCl} / \mathrm{pH} 7.0 / 8 \mathrm{M}$ urea/10 mM dithiotreitol, then incubated for $30 \mathrm{~min}$ at $37^{\circ} \mathrm{C}$. The sample was buffer exchanged into PBS/ $1 \mathrm{mM}$ EDTA/ 2 M urea using a Centricon YM-3 (3000 MW cutoff) at $4^{\circ} \mathrm{C}$. Fifty $\mu \mathrm{l}$ of $4 \mathrm{mM}$ EZ-Link ${ }^{\text {TMBiotin-HPDP }}$ (Pierce, Rockford, IL, USA) in DMSO was added and the sample incubated at room temperature for $90 \mathrm{~min}$. To remove excess free BiotinHPDP the sample was buffer exchanged again into PBS/1 mM EDTA/ $2 \mathrm{M}$ urea, followed by trypsin digestion as above. An $1 \mathrm{~mL}$ ImmobilizedAvidin column (Pierce, Rockford, IL, USA) was equilibrated with $5 \mathrm{ml}$ PBS/1 mM EDTA. The biotinylated digest was applied to the column and incubated for $30 \mathrm{~min}$ at room temperature. The avidin column was washed with $10 \mathrm{~mL}$ PBS/1 mM EDTA (yielding the flowthrough fraction). Two $\mathrm{mL}$ of PBS/50 mM dithiotreitol was added to elute any bound peptides (yielding the bound fraction). Both the avidin flowthrough fraction and the avidin bound fraction were alkylated (using 10 and $100 \mathrm{mM}$ iodoacetamide respectively) for $30 \mathrm{~min}$ at room temperature. The fractions were acidified with formic acid, desalted using an Oasis cartridge (Waters, Milford, MA, USA), vacuum concentrated, and then resuspended in $100 \mu \mathrm{l} 0.1 \%$ formic acid. LC-MS/MS analysis was performed using the above listed parameters but with a $\mathrm{C} 18$ $0.05 \times 150 \mathrm{~mm}$ column (MetaChem Technologies Inc., Torrance, CA, USA) and a flow rate of $25 \mu \mathrm{l} / \mathrm{min}$ without splitting directly into the mass spectrometer. Four separate LC-MS/MS runs using separate narrow mass ranges for ion selection $(400-575,565-715,685-970$, and $935-2000 \mathrm{~m} / \mathrm{z}$ ) were used for the flowthrough fraction and the bound fraction was analyzed using the single broad mass range $(400-2000 \mathrm{~m} /$ $z$ for ion selection. Spectra were handled as described above.

\section{Immunofluorescence}

Mouse embryonic fibroblasts were cultured in the absence or presence of the apoptosis inducer staurosporin (STS; $2 \mu \mathrm{M}, 4 \mathrm{~h}$; Sigma). A rabbit antiserum generated against DDP 37 was used (diluted 1/20) on paraformaldehyde ( $4 \% \mathrm{w:v})$ and picric acid-fixed $(0.19 \%$ v:v) cells (cultured on $100 \mu \mathrm{m}$ cover slips; $18 \mathrm{~mm} \varnothing$; Superior, Germany), and revealed with a goat anti-rabbit IgG conjugated to phycoerythrine (PE) (Southern Biotechnology, Birmingham, AL, USA). A sheep antiserum specific for SOD2 (Calbiochem, San Diego, CA, USA) was revealed by means of a rabbit anti-sheep IgG fluorescein isothiocyanate (FITC) conjugate (Southern Biotechnology). Cells were counterstained for the detection of hsp60 (mAb H4149 from Sigma, revealed by a goat antimouse IgG FITC or PE conjugate; Southern Biotechnology). Confocal microscopy was performed on a Leica TC-SP (Leica Microsystems, Heidelberg, Germany) equipped with an ArKr laser mounted on an inverted Leica DM IFBE microscope with a $63 \times 1,32$ NA oil objective.

\section{Acknowledgements}

This work has been supported by a special grant from the Ligue Nationale contre le Cancer as well as grants from ANRS and FRM (to G Kroemer), Assistance Publique-Hôpitaux de Paris and CANAM (contract 98006 to $\mathrm{E}$ Daugas).

\section{References}

1. Kroemer G (1997) Mitochondrial implication in apoptosis. Towards an endosymbiotic hypothesis of apoptosis evolution. Cell Death Differ. 4: 443-456

2. Kroemer G, Dallaporta B and Resche-Rigon M (1998) The mitochondrial death/ life regulator in apoptosis and necrosis. Annu. Rev. Physiol. 60: 619-642

3. Susin SA, Zamzami N, Castedo M, Daugas E, Wang H-G, Geley S, Fassy F, Reed $J$ and Kroemer $G$ (1997) The central executioner of apoptosis. Multiple links between protease activation and mitochondria in Fas/Apo-1/CD95- and ceramide-induced apoptosis. J. Exp. Med. 186: 25-37

4. sSteemans M, Goossens V, Van de Craen M, Van Herreweghe F, Vancompernolle K, De Vos K, Vandenabeele P and Grooten J (1998) A caspase-activated factor (CAF) induces mitochondrial membrane depolarization and cytochrome c release by a non-proteolytic mechanism. J. Exp. Med. 188: 2193-2198 
5. Jürgensmeier JM, Xie Z, Deveraux Q, Ellerby L, Bredesen D and Reed JC (1998) Bax directly induces release of cytochrome $\mathrm{c}$ from isolated mitochondria. Proc. Natl. Acad. Sci. U.S.A. 95: 4997-5002

6. Marzo I, Brenner C, Zamzami N, Jürgensmeier J, Susin SA, Vieira HLA, Prévost M-C, Xie Z, Mutsiyama S, Reed JC and Kroemer G (1998) Bax and adenine nucleotide translocator cooperate in the mitochondrial control of apoptosis. Science 281: 2027-2031

7. Li H, Zhu H, Xu C and Yuan J (1998) Cleavage of BID by caspase 8 mediates the mitochondrial damage in the Fas pathway of apoptosis. Cell 4: 491-501

8. Scorrano L, Petronilli V, Di Lisa F and Bernardi P (1999) Commitment to apoptosis by GD3 ganglioside depends on opening of the mitochondrial permeability transition pore. J. Biol. Chem. 274: 22581-22585

9. Zamzami N, Susin SA, Marchetti P, Hirsch T, Gómez-Monterrey I, Castedo Mand Kroemer G (1996) Mitochondrial control of nuclear apoptosis. J. Exp. Med. 183: $1533-1544$

10. Susin SA, Zamzami N, Castedo M, Hirsch T, Marchetti P, Macho A, Daugas E, Geuskens M and Kroemer G (1996) Bcl-2 inhibits the mitochondrial release of an apoptogenic protease. J. Exp. Med. 184: 1331-1342

11. Zamzami N, Marzo I, Susin SA, Brenner C, Larochette N, Marchetti P, Reed J, Kofler $R$ and Kroemer $G$ (1998) The thiol-crosslinking agent diamide overcomes the apoptosis-inhibitory effect of $\mathrm{Bcl}-2$ by enforcing mitochondrial permeability transition. Oncogene 16: 1055-1063

12. Shimizu S, Narita M and Tsujimoto Y (1999) Bcl-2 family proteins regulate the release of apoptogenic cytochrome $\mathrm{c}$ by the mitochondrial channel VDAC. Nature 399: 483-487

13. Brenner C, Cardiou H, Vieira HLA, Zamzami N, Marzo I, Xie Z, Leber B, Andrews D, Duclohier H, Reed JC and Kroemer G (1999) Bcl-2 and Bax regulate the channel activity of the mitochondrial adenine nucleotide translocator. Oncogene. In press.

14. vander Heiden MG, Chandal NS, Williamson EK, Schumacker PT and Thompson CB (1997) Bcl-XL regulates the membrane potential and volume homeostasis of mitochondria. Cell 91: 627-637

15. LiuXS, Kim CN, Yang J, Jemmerson Rand Wang X (1996) Induction of apoptotic program in cell-free extracts: requirement for dATP and cytochrome C. Cell 86: $147-157$

16. Single B, Leist $M$ and Nicotera $P$ (1998) Simultaneous release of adenylate kinase and cytochrome $c$ in cell death. Cell Death Differ. 5: 1001-1003

17. Kohler C, Gahm A, Noma T, Nahazawa A, Orrenius S and Zhivotovsky B (1999) Release of adenylate kinase 2 from the mitochondrial intermembrane space during apoptosis. FEBS Lett. 447: 10-12

18. Susin SA, Zamzami N, Castedo M, Hirsch T, Marchetti P, Macho A, Daugas E, Geuskens M and Kroemer G (1996) Bcl-2 inhibits the mitochondrial release of an apoptogenic protease. J. Exp. Med. 184: 1331-1342

19. Susin SA, Lorenzo HK, Zamzami N, Marzo I, Snow BE, Brothers GM, Mangion J, Jacotot E, Costantini P, Loeffler M, Larochette N, Goodlett DR, Aebersold R, Siderovski DP, Penninger JM and Kroemer G (1999) Molecular characterization of mitochondrial apoptosis-inducing factor (AIF). Nature 397: 441-446

20. Susin SA, Lorenzo HK, Zamzami N, Marzo I, Larochette N, Alzari PM and Kroemer G (1999) Mitochondrial release of caspase-2 and -9 during the apoptotic process. J. Exp. Med. 189: 381-394

21. Krajewski S, Krajewska M, Ellerby LM, Welsh K, Xie ZH, Deveraux QL, Salvesen GS, Bredesen DE, Rosenthal RE, Fiskum G and Reed JC (1999) Release of caspase-9 from mitochondria during neuronal apoptosis and cerebral ischemia. Proc. Natl. Acad. Sci. U.S.A. 96: 5752-5757

22. Samali A, Cai J, Zhivotovsky B, Jones DP and Orrenius S (1999) Presence of a pre-apoptotic complex of procaspase-3, hsp60, and hsp10 in the mitochondrial fraction of Jurkat cells. EMBO J. 18: 2040-2048

23. Lorenzo HK, Susin SA, Penninger J and Kroemer G (1999) Apoptosis inducing factor (AIF): a phylogenetically old, caspase-independent effector of cell death. Cell Death Differ. 6: 516-524

24. Mintz PS, Patterson SD, Neuwald AF, Spahr CS and Spector DL (1999) Purification and biochemical characterisation of interchromatin granule clusters. EMBO J. 18: 4308-4320

25. Link AS, Eng J, Schielzts DM, Carack E, Mize GJ, Morris DR, Garvik BM and Yates III JR (1999) Direct analysis of protein complexes using mass spectrometry. Nat. Biotechnol. 17:676-682
26. Patterson SD Using MS fragment-ion data to identify proteins from large sequence databases. In: Proteomics, Integrating Protein-based tools and application for drug discovery. L.M. Savage (ed.). International Business Communications, Inc.: Southborough pp. 127-135, 1998

27. Vancompernolle K, Van Herrewghe F, Pynaert G, Van de Craen M, De Vos K, Totty N, Sterling A, Fiers W, Vandenabeele P and Grooten J (1998) Atractylosideinduced release of cathepsin $B$, a protease with caspase-processing activity. FEBS Lett. 6: 150-158

28. Voilley N, Roduit R, Vicaretti R, Bonny C, Waeber G, Dyck JRB, Lopaschuk GD and Prentki M (1999) Cloning and expression of rat pancreatic beta-cell malonyl CoA decarboxylase. Biochem. J. 340:213-217

29. Ashmarina LI, Psheshetsky AV, Branda SS, Isaya G and Mitchell GA (1999) 3hydroxy-3-methylglutaryl coenzyme A lysase: targeting and processing in peroxisomes and mitochondria. J. Lipid. Res. 40: 70-75

30. Danpure CJ (1997) Variable peroxisomal and mitochondrial targeting of alanine glyoxylate aminotransferase in mammalian evolution and disease. Bioessays 19: $317-326$

31. Xanthoudakis S, Roy S, Rasper D, Hennessey T, Aubin Y, Cassady R, Tawa P, Ruel R, Rosen A and Nicholson DW (1999) Hsp60 accelerates the maturation of pro-caspase-3 by upstream activator proteases during apoptosis. EMBO J. 18 : 2049-2056

32. Narita M, Shimizu S, Ito T, Chittenden T, Lutz RJ, Matsuda H and Tsujimoto $Y$ (1998) Bax interacts with the permeability transition pore to induce permeability transition and cytochrome c release in isolated mitochondria. Proc. Natl. Acad. Sci. U.S.A. 95: $14681-14686$

33. Marchetti P, Hirsch T, Zamzami N, Castedo M, Decaudin D, Susin SA, Masse B and Kroemer $G$ (1996) Mitochondrial permeability transition triggers lymphocyte apoptosis. J. Immunol. 157: 4830-4836

34. Hirsch T, Decaudin D, Susin SA, Marchetti P, Larochette N, Resche-Rigon Mand Kroemer G (1998) PK11195, a ligand of the mitochondrial benzodiazepin receptor, facilitates the induction of apoptosis and reverses Bcl-2-mediated cytoprotection. Exp. Cell. Res. 241: 426-434

35. Miccoli L, Poirson-Bichat F, Sureau F, Gonçalves RB, Bourgeois Y, Dutrillaux B, Poupon M-F and Oudard S (1998) Potentiation of lonidamine and diazepam, two agents acting on mitochondria, in human glioblastoma treatment. J. Natl. Cancer Inst. 90: 1400-1406

36. Carthy CM, Granville DJ, Jiang HJ, Levy JG, Rudin CM, Thompson CB, McManus BM and Hunt DWC (1999) Early release of mitochondrial cytochrome $C$ and expression of mitochondrial epitope $7 \mathrm{~A} 6$ with a porphyrin-derived photosensitizer: Bcl-2 and Bcl-XL overexpression do not prevent early mitochondrial events but still depress caspase activity. Lab. Invest. 79: 953-965

37. Koehler CM, Leuenberger D, Merchant S, Renold A, Junne T and Schatz G (1999) Human deafness dystonia syndrome is a mitochondrial disease. Proc. Natl. Acad. Sci. U.S.A. 96: 2141-2146

38. Merrick BA, He CV, Witcher LL, Patterson RM, Reid JAJ, Pence Pawlowski PM and Selkirk JK (1996) HSP binding and mitochondrial localization of p53 protein in human HT1080 and mouse C3H10T1/2 cell lines. Biochim. Biophys. Acta 1297: $57-68$

39. Zamzami N, Marchetti P, Castedo M, Decaudin D, Macho A, Hirsch T, Susin SA, PetitPX, Mignotte B and Kroemer G (1995) Sequential reduction of mitochondrial transmembrane potential and generation of reactive oxygen species in early programmed cell death. J. Exp. Med. 182: 367-377

40. Susin SA, Larochette N, Geuskens M and Kroemer G (1999) Purification of mitochondria for apoptosis assays. Methods Enzymol. in press

41. Pedersen PL, Grennawalt JW, Reynafarje B, Hullihen J, Decker GL, Soper JW and Bustamente $E$ (1978) Preparation and characterization of mitochondria and submitochondrial particles of rat liver and liver-derived tissues. Meth. Cell Biol. 20: $411-481$

42. Courchesne PL, Jones MD, Robinson JH, Spahr CS, McCracken S, Bentley DL, Luethy R and Patterson SD (1998) Optimization of capillary chromatography ion trap mass spectrometry for identification of gel-separated proteins. Electrophoresis 19: 956-967

43. Courchesne PL, Luethy Rand Patterson SD (1997) Comparison of in-gel and onmembrane digestion methods at low to sub-pmol level for subsequent peptide and fragmentation mass analysis uding matrix-assisted laser-desorption ionization mass spectrometry. Electrophoresis 18: $369-381$ 